\title{
DIFICULDADES DA INCLUSÃO DE PESSOAS COM DEFICIÊNCIA NO MERCADO DE TRABALHO
}

\section{DIFFICULTIES IN INCLUDING PEOPLE WITH DISABILITIES IN THE LABOUR MARKET}

\section{Eulália Xavier Miranda}

Acadêmica do $7^{\circ}$ período em Administração pela Alfa Unipac, Aimorés/MG, Brasil

E-mail: eulaliaxavier01@gmail.com

\section{Charleston Sperandio de Souza} Mestre e Professor de Administração pela Alfa Unipac, Aimorés/MG, Brasil E-mail: charleston.sperandio@yahoo.com.br Recebido: 00/03/2020 - Aceito: 00/00/2020

\section{Resumo}

O presente artigo buscou resgatar a história das Pessoas com Deficiências (PcD's), entendê-las e descobrir o porquê a inclusão do deficiente no mercado de trabalho é um problema para as empresas, a partir de pesquisas teóricas. Ao analisar o estudo, pode-se perceber que se abordou alguns tópicos como: As definições dos tipos de deficiências; relação de população com deficiência no Brasil; a legislação que assegura os mesmos e em especial a Lei de Cotas. O estudo foi de caráter qualitativo com análise de revisão da literatura. Justificou-se a importância deste tema, pois além de trazer respostas para uma sociedade específica, mostra como vem sendo tratado essa questão da inclusão, pois ainda encontramos vários mitos e barreiras. Evidenciou-se que algumas iniciativas de melhorias, como: Conscientização nas escolas e nas empresas sobre este assunto; fiscalização constante para que se assegure o cumprimento da lei; rampasem locais públicos de difíceis acessos, entre outros. Essas são umas medidas necessárias para que o preconceito acabe e a aceitação das empresas sejam maiores, pois as PcD's podem ser muitas vezes o maior capital intelectual de uma empresa. Os resultados do artigo apontam claramente que não há desvantagens para os empresários que contratam esses profissionais. A inclusão dos PCD's nas empresas é capaz ainda de atrair novos tipos de consumidores, além de promover uma reabilitação social e psicológica, já que o sentimento de produtividade contribui para melhorar a qualidade de vida profissional.

Palavras-chave: Pessoas com deficiência; inclusão; mercado de trabalho. 


\section{Abstract}

This article sought to retrieve the history of People with Disabilities (PwD's), understand them and discover why the inclusion of the disabled in the labor market is a problem for companies, based on theoretical research. When analyzing the study, it can be seen that some topics were addressed, such as: The definitions of the types of disabilities; relationship of disabled population in Brazil; the legislation that ensures them and in particular the Quota Law. The study was qualitative with analysis of literature review. The importance of this theme was justified, because in addition to bringing answers to a specific society, it shows how this issue of inclusion has been treated, as we still find several myths and barriers. Some improvement initiatives were mentioned in the article, such as: Awareness raising in schools and companies on this subject; constant inspection to ensure compliance with the law; ramps in public places with difficult access, among others. These are necessary measures for the prejudice to end and the acceptance of companies to be greater, as PwD's can often be the greatest intellectual capital of a company. The results of the article clearly show that there are no disadvantages for entrepreneurs who hire these professionals. The inclusion of PCD's in companies is also capable of attracting new types of consumers, in addition to promoting social and psychological rehabilitation, since the feeling of productivity contributes to improving the quality of professional life.

Keywords: People with disabilities; inclusion; labor market.

\section{Introdução}

Embora a consolidação da concepção de cidadania, atualmente esteja em plena garantia, muitas pessoas que possuem necessidades especiais têm dificuldade de serem reconhecidas perante o mercado de trabalho.

É importante dar respaldo ao assunto, diagnosticar os motivos que levam as PcD's a ficar fora do mercado de trabalho e o que já tem sido feito para melhorar, como, por exemplo, as leis de incentivo que os amparam. A pesquisa dos autores Nascimento et al (2008), analisou que a dificuldade de contratação se dá pela falta de divulgação e informação sobre o processo de inclusão nas empresas.

Segundo Costa (2012), o Brasil é um país o qual ainda possui dificuldades em aceitação de PcD's no mercado de trabalho, mesmo elas tendo seus direitos assegurados por Lei de Cotas.

Assim, o tema abordado se torna oportuno para ser pesquisado, pois tem como principal objetivo entender os motivos que as empresas ainda tem resistência perante a sociedade de PcD's. 
Nessa linha, o presente estudo justifica-se por entender ser pertinente à compreensão do tema abordado. Torna-se relevante pesquisar sobre o mesmo, já que a informação proporciona às pessoas aos conhecimentos dos seus direitos e as soluções que resolvam esse impasse de maneira séria e competente.

A fundamentação teórica se baseia na literatura encontrada nos autores Sassaki, R.K (2006), Bartalotti, C. C (2006), Bahia, M.S (2006), que fazem análises importantes sobre o tema e que inspira na criação de um artigo deste assunto.

A deficiência é o termo utilizado para definir a falta ou a disfunção de uma estrutura psíquica, fisiológica ou anatômica.

\subsection{Tipos de Deficiências}

As deficiências podem ser: intelectual, visual, auditiva, física ou múltipla, congênita ou não. De acordo com Diniz (2009), o novo conceito supera a ideia de impedimento como sinônimo de deficiência, reconhecendo, na restrição de participação, o fenômeno que determina a identificação da desigualdade causada pela deficiência.

Segundo o Decreto № 3.289 de 20 de Dezembro de 1999, se existir perda ou anomalia de qualquer estrutura ou função psicológica, fisiológica e/ou anatômica, que faça com que a pessoa tenha incapacidade total ou imparcial, que impeça a mesma de garantir segurança para si mesma ou 0 atendimento às suas necessidades de vida, social ou individual, podendo ser deficiência temporária ou permanente:

- Deficiência Temporária: é a limitação que pode ser revertido por meio de cirurgias ou tratamentos contínuos ou não;

- Deficiência Permanente: é aquela que se estabilizou após um determinado período de tempo e que impede a regressão ou recuperação do paciente.

Ao analisar os dados de 2013 do Instituto Brasileiro de Geografia e Estatística (IBGE), mais de 6,2\% da população brasileira possuem algum tipo de deficiência, seja ela intelectual, visual, auditiva, física ou múltipla.

De todos os tipos de deficiências pesquisadas, a visual é a mais representativa e atinge $3,6 \%$ dos brasileiros, sendo mais comum entre as pessoas 
com mais de 60 anos (11,5\%). O grau agudo ou muito agudo da limitação impossibilita $16 \%$ dos deficientes visuais de realizarem atividades habituais como ir à escola, trabalhar e brincar (IBGE, 2013).

De acordo com o estudo, 1,3\% da população têm algum tipo de deficiência física e quase a metade desse total $(46,8 \%)$ tem grau agudo ou muito agudo de limitações (IBGE, 2013).

Ainda de acordo com o IBGE, $0,8 \%$ da população brasileira têm algum tipo de deficiência intelectual, e a maioria $(0,5 \%)$ possui deficiência congênita.

Do total de pessoas com deficiência intelectual, mais da metade $(54,8 \%)$ tem grau intenso ou muito agudo de limitação (IBGE, 2013).

Nessa linha, cerca de $1,1 \%$ da população brasileira apresenta deficiência auditiva, e esse tipo de deficiência foi o único que apresentou resultados estatisticamente diferenciados por cor ou raça, sendo mais comum em pessoas brancas $(1,4 \%)$, do que em negros $(0,9 \%)$ e cerca de $0,9 \%$ dos brasileiros ficaram surdos em decorrência de alguma doença ou acidente e $0,2 \%$ é congênito. Do total de deficientes auditivos, $21 \%$ têm grau agudo ou muito agudo de limitações, o que compromete atividades habituais, como trabalhar (IBGE, 2013).

De acordo com Lanna Júnior (2010), a partir do século XX, as pessoas com deficiência começaram a apresentar conquistas no combate ao preconceito e à luta pela garantia dos direitos da comunidade PcD's.

No ano de 1940, constataram-se vários movimentos a favor da integração dessa comunidade no mercado de trabalho, mas, infelizmente, esses movimentos foram retraídos pelo cenário internacional. Nesse mesmo ano, com a criação da Declaração Universal dos Direitos Humanos, teve início um amplo debate sobre o assunto de direito e igualdade, como base da liberdade, justiça e paz no mundo.

Figueira (2008) relata que as pessoas com deficiência conseguiram chegar até os dias atuais sem nenhuma ajuda, excluída ou segregada em entidades.

A partir de 1981, o Ano Internacional da Pessoa Deficiente, criado pela ONU, passou a se organizar politicamente para intervir por essas pessoas. No decorrer do mesmo século, foram criadas escolas para crianças com deficiências mentais (atualmente chamada de doença intelectual), nas redes paralelas ao ensino fundamental da época, devido à omissão do Estado ao prestar apoio a essas crianças. 
Atualmente, existem associações que vem intervindo na educação das crianças, criando escolas adaptadas para elas, como, por exemplo, a Associação de Pais e Amigos dos Excepcionais (APAE), (FIGUEIRA, 2008).

\subsection{O Direitos Constitucionais dos PcD's}

A Constituição Federal Brasileira (1988), foi um marco importante no avanço à integração e proteção dos PcD's por parte do Estado, na qual foram criadas leis que assegurem melhorias na condição de vida, educação especial e gratuita, assistência e, principalmente, a reabilitação e sua reinserção na vida econômica e social do país.

No dia 11 de dezembro de 1990 foi aprovada a Lei $n^{\circ}$ 8.112, a qual revolucionaria a luta pela integração das PcD's no mercado de trabalho, já que essa lei utiliza somente o regime jurídico dos servidores públicos civis das Autarquias, União e das Fundações Públicas Federais que compromete em seu Art. 5oㅡ, § 2o ficou estabelecido que:

a) Às pessoas com deficiência é assegurado o direito de se inscrever em concurso público para provimento de cargo cujas atribuições sejam compatíveis com a deficiência de que tenham; para tais pessoas serão reservadas até $20 \%$ (vinte por cento) das vagas oferecidas no concurso.

Essa lei veio para assegurar o direito aos PcD's a disputarem, via concurso público, por cargos que competem com suas deficiências, sendo que $20 \%$ das vagas oferecidas em editais devem ser reservadas às pessoas com deficiência.

Para garantir o acesso ao trabalho para as PCD's foi assegurada pela Lei № 8.213, de 24 de Julho de 1999, porém, passou a apresentar eficiência no final do ano de 1999, quando foi publicado o decreto № 3.298 , o qual determina que as pessoas com mais de cem empregados contratem um percentual de pessoas com deficiência, dede que o trabalho que irá exercer seja compatível com sua doença, segundo as seguintes cotas:

- Até 200 funcionários: $2 \%$

- 201 a 500 funcionários: $3 \%$

- 501 a 1000 funcionários: $4 \%$

- Mais de 1001:5\% 
De acordo com as pesquisas do autor Sassaki (2006), a integração de PcD's nas empresas propõe a inserção parcial do sujeito, enquanto que a inclusão propõe a inserção total.

Bahia (2006), contradiz, dizendo que pessoas com deficiências são tidas como peso morto pelas empresas e que é isso que dificulta a inclusão no mercado de trabalho. O Ministério Público adverte que ainda nos dias atuais, não existem multas para os empresários que não obedecem que o determina a Lei de Cotas.

A ação fiscalizadora do Ministério Público vem fazendo com que as empresas, que atua de acordo com a legislação, estimulem o aumento do número de vagas destinadas às pessoas com deficiência previstas na lei.

A Lei 8.213/91 tem mais de vinte anos e vem conseguindo elevar o número de deficientes no mercado de trabalho, ainda com a existência de rejeição por parte das empresas. Constata-se que, mesmo com este tempo de vigência, o Ministério Público não consegue fazer com que os empresários recebam autuações por não atenderem a lei.

O Brasil validou duas normas internacionais para se compreender o conceito de deficiência física. Essas normas são:

a) Convenção da Organização Internacional do Trabalho (OIT) e a

b) Convenção da Guatemala, que tratam da proteção de pessoas com limitações, sejam elas físicas, sensoriais, intelectuais, ou mentais, e que limitem a execução de atividades normais do cotidiano.

Ainda de acordo com o Ministério do Trabalho, nos últimos 5 anos, no Brasil, houve um aumento de $20 \%$ da comunidade PcD's no mercado de trabalho.

Grandes empresas, bancos e indústrias abriram as portas para as pessoas que eram excluídas pela sociedade, pelas empresas e por suas limitações. Hoje em dia, as funções que são delegadas a estas pessoas estão em um cenário de mudança, pois antes os PcD's atuavam apenas nos bastidores, e hoje prestam serviços de atendimento e, muitas vezes, estão na linha de frente em critérios de decisões dentro da organização.

Sassaki (2006) reforça que uma empresa a qual pratica a inclusão, é aquela que acredita no valor da diversidade humana e admira as diferenças individuais, realiza mudanças administrativas, faz adaptações no ambiente físico da empresa, 
adapta os instrumentos de trabalho e oferece treinamento para todos os funcionários na questão de inclusão.

Para Bartalotti (2006), é importante reafirmar que a inclusão não se limita ao acesso e sim na questão geral da empresa, principalmente, no que diz respeito à aceitação de todos os recursos humanos da empresa.

A integração e a inclusão no mercado de trabalho, é um direito e segundo Clemente (2003) a falta de informação e conhecimento sobre a comunidade PcD's e suas limitações ainda é um empecilho, o qual faz com que a convivência não-segregada e a falta de recursos disponíveis resultem na discriminação e exclusão dessa população.

A contratação de um PcD's nas empresas é apenas um começo de etapa de inclusão de pessoas com deficiências no mercado de trabalho, já a permanência requer outras medidas importantes. Não excluir as pessoas com deficiência do convívio com o restante da empresa e não as isolarem em setores criados para pessoas com deficiência são medidas fundamentais para que ocorra um real processo de inclusão.

Outro ponto importante, é saber que ajustes serão necessários durante a implementação do programa, pois novas questões podem surgir de complexidade variável (INSTITUTO ETHOS, 2002).

Por fim e ainda de acordo com o Instituto Ethos (2002), muitas questões são levadas em consideração pelas empresas na hora da contratação: em primeiro lugar, a inexperiência das pessoas da empresa em conviver com pessoas com deficiência; em segundo, a precária educação e profissionalização da maioria delas; e, em terceiro, a acessibilidade desses profissionais dentro da organização.

\section{Metodologia}

O estudo do presente artigo foi fundamentado em teóricos que apresentam significativa importância na definição e construção dos conceitos apresentados nesta análise: Dificuldades da inclusão de pessoas com deficiência no mercado de trabalho. 
Para isso, tais objetos serão estudados em fontes secundárias como trabalhos acadêmicos, artigos, livros e afins, que foram selecionados para estudos, para ser desenvolvido o presente artigo.

Segundo Galliano (1986) o conhecimento da metodologia científica vai além de analisar um fato, mas também de descobrir suas relações com outros fatos existentes e explicá-los.

Ciribelli (2003) corrobora dizendo que o método científico pode ser conceituado como etapas e instrumentos que o pesquisador cientifico usa para projetos de caráter cientifico para poder alcançar os objetivos da pesquisa realizada.

Com o intuito de obter as interpretações por meio da subjetividade, foi realizada uma análise remontada em estudos de alguns autores que discutem o tema como Romeu Kazumi Sassaki, Celina Camargo Bartalotti, Lanna Júnior e Maria Salete, entre outros pensadores que elaboraram trabalhos pertinentes ao assunto; e algumas leis brasileiras com o intuito de desenvolver familiaridade com 0 tema da pesquisa de forma a entender o tema abordado por meio da pesquisa exploratória.

De acordo com Rodrigues (2007), a pesquisa exploratória é um método utilizado para formalizar o assunto surgido durante as pesquisas, explorando os próximos passos mais profundamente e com maior precisão.

Assim sendo, o trabalho avançou a partir do método conceitual-analítico, visto que foram utilizados conceitos e idéias de outros autores, para a construção de uma análise científica sobre objeto de estudo.

O método de pesquisa escolhido favoreceu uma liberdade na análise de se mover por diversos caminhos do conhecimento, além de apresentar uma forma mais clara do entendimento do tema, possibilitando assumir várias posições no decorrer do percurso.

O estudo teve caráter qualitativo, com ênfase no cruzamento dos levantamentos com toda a pesquisa bibliográfica já feita no decorrer dos anos, para que o trabalho apresentado tivesse informações que sustentasse a ideia principal do artigo.

Por fim, Richardson (1999), diz que a pesquisa qualitativa é válida em situações que se evidencia a importância de compreender o tema, cujos dados não podem ser coletados de maneira completa, devido à complexidade que encerram. 


\section{Resultados e Discussão}

Após de analisar as interpretações teóricas acerca do tema explicitado, os resultados realizados no presente estudo, não paira dúvida que o importante foi identificar por que existe muitas dificuldades em fazer com que as empresas contratem a mão de obra PcD's.

Partindo desse pressuposto, foi possível encontrar possíveis soluções para estes impasses, uma delas é por meio da conscientização dos empresários, e o acompanhamento das empresas para que sejam cumpridas às leis exigidas.

Tendo como base a literatura e os conceitos dos autores sobre o tema, foram desenvolvidas algumas sugestões de melhorias, para que seja compreendido o objetivo do trabalho da melhor forma possível, tendo em vista, fazer com que a contratação de PcD's não seja um problema e sim a solução para a empresa.

A partir dos resultados obtidos percebe-se o quanto ainda é difícil a inclusão de PcD's no mercado de trabalho, mas existem soluções para que este impasse seja resolvido. $O$ artigo trouxe contribuiu com algumas ideias de melhorias para atribuírem na realidade da sociedade.

Após as mesmas serem implantadas, pode ser acompanhado o seu desenvolvimento, pelo Estado e também pelos órgãos responsáveis, para que aumente o numero de contratação de PcD's.

\section{Conclusão}

O presente trabalho pretendeu expor o conceito de pessoas com deficiência, os tipos de deficiências, as barreiras enfrentadas pela PcD's e também apresentar as leis que os protegem.

O intuito do estudo foi apresentar contribuições necessárias para que sirvam de embasamento para criação de novos artigos e trabalhos.

Contudo, se fez necessário, descobrir por meio dos estudos teóricos, quais são as barreiras que impedem a contratação de PcD's e o que tem feito para que isso mude. 
Com os estudos bibliográficos, revelou-se que as maiores dificuldades que as pessoas com deficiências enfrentam diante uma contratação, é o preconceito, a falta de informação, a falta de interesse dos empresários, a falta de capacitação e o conhecimento das Leis que favorecem e garantem os direitos desta população.

Observou-se que esta situação das PcD's ainda tem que ser muito debatida e estudada, para que se criem novas informações educativas.

Por este motivo sugere-se que algumas melhorias, para que seja amenizado o impasse da contratação da mão de obra PcD, são elas:

a) Programas nas escolas e empresas com atividades e palestras que conscientizem a todos as particularidades e direitos das PcD's;

b) Aumentar as fiscalizações nas empresas para que seja observado se as Leis de Cotas estão sendo devidamente seguidas;

c) Garantir acessibilidade em ambientes públicos, transportes públicos, instituições de ensino e vias de acesso como calçadas e isso não apenas nas vias mais movimentadas; e

d) Fazer com que escolas e faculdades tenham profissionais capacitados para receber as PcD's, garantido assim, uma melhor capacidade de aprendizagem dos mesmos.

Recomenda-se que outros trabalhos sejam desenvolvidos para ampliar a compreensão acadêmica e profissional sobre o assunto, criar novas sugestões para que ajude a resolver e conscientizar as PcD's e aos proprietários das empresas sobre a vantagem da contratação de pessoas com deficiências nas empresas.

\section{Referências}

BAHIA, Melissa S. Responsabilidade Social e Diversidade nas Organizações: Contratando Pessoas com Deficiência. Rio de Janeiro: Qualitymark, 2006.

BARTALOTTI, C.C. Inclusão social das pessoas com deficiência: utopia ou possibilidade? São Paulo: Paulus, 2006.

BRASIL. Constituição da República Federativa do Brasil: D.O. 5 de outubro de 1988. Disponível em <www.mec.gov.br/legis/default.shtm. >. Acesso em 07 de setembro de 2019. 
, Lei № 11180, de 23 de setembro de 2005. Disponível em:

<https://www.planalto.gov.br/ccivil_03/leis/2002//10436.htm>. Acesso em: 07 de setembro de 2019.

Lei № 3289, de 20 de dezembro de 1999. Disponível em: <https://www.planalto.gov.br/ccivil_03/leis/2002/l10436.htm>. Acesso em: 07 de setembro de 2019.

Lei № 8112, de 11 de dezembro de 1990. Disponível em: <https://www.planalto.gov.br/ccivil_03/leis/2002/l10436.htm>. Acesso em: 07 de setembro de 2019.

Lei № 8213, de 11 de julho de 1999. Disponível em:

<https://www.planalto.gov.br/ccivil_03/leis/2002/l10436.htm>. Acesso em: 07 de setembro de 2019.

, Lei № 8213, de 24 de julho de 1991. Disponível em:

<https://www.planalto.gov.br/ccivil_03/leis/2002/l10436.htm>. Acesso em: 07 de setembro de 2019.

CIRIBELLI, Marilda Corrêa. Como elaborar uma dissertação de Mestrado através da pesquisa científica. Marilda Ciribelli Corrêa, Rio de Janeiro: 7 Letras, 2003.

CLEMENTE, Carlos Aparício. Trabalho e inclusão social de portadores de deficiência. Osasco: Ed Pares, 2003.

COSTA, S. M. Dignidade humana e pessoa com deficiência: aspectos legais e trabalhistas. São Paulo: LTr, 2012.

DINIZ, Debora; BARBOSA, Lívia; SANTOS, Wederson Rufino dos. Deficiência, Direitos Humanos e Justiça. Sur, Rev. int. direitos human. vol.6, n.11, São Paulo, Dec./2009.

ETHOS, Instituto. O que as empresas podem fazer pela inclusão de pessoas com deficiência. São Paulo: Instituto Ethos, 2002.

FIGUEIRA, Emilio, Caminhando em Silêncio: Uma introdução à trajetória da pessoa com deficiência na história do Brasil. São Paulo, Giz Editorial, 2008.

GALLIANO, Alfredo Guilherme. O método científico: teoria e prática. São Paulo: Harbra, 1986.

IBGE. Dados sobre pessoas com deficiência 2015. Disponível em <www.ibge.gov.br>. Acesso em: 07 de setembro de 2019.

Censo Demográfico 2013. Características gerais da população, religião e pessoas cm deficiência. IBGE. 2012. Disponível em <www.ibge.com.br>. Acesso em 7 de setembro de 2019. 
LANNA JUNIOR, Mário Cléber Martins (Comp.). História do Movimento Político das Pessoas com Deficiência no Brasil. - Brasília: Secretaria de Direitos Humanos. Secretaria Nacional de Promoção dos Direitos da Pessoa com Deficiência, 2010.

MINISTÉRIO DO TRABALHO. A inclusão de pessoas com deficiência no mercado de trabalho.2. ed. Brasília: MTE, SIT,2007. Disponível em <http://www.mte.gov.br>. Acesso em 07 de setembro de 2019.

NASCIMENTO et al. Mercado de trabalho para as pessoas com deficiência em Betim/MG. In: EnANPAD, 32, 2008, Rio de Janeiro. Anais...Rio de Janeiro, 2008.

RICHARDSON, R. J. Pesquisa social: métodos e técnicas. São Paulo: Atlas, 1999.

RODRIGUES, William Costa. Metodologia Científica, 2007. Disponível em: $<$ http;/unisc.br/portal/uplod/com_arquivo/metodologia_cientifica.pdf. $>$. Acesso em 26 de outubro de 2019.

SALOMAO, P. E. A. et al. As Tecnologias de Informação e Comunicação (TIC) no ensino superior. Revista Multidisciplinar do Nordeste Mineiro, v. 1, 2018.

SASSAKI, R.K. Inclusão construindo uma sociedade para todos.7. Ed. Rio de Janeiro: WVA, 2006. 